J. Neurol. Neurosurg. Psychiat., 1958, 21, 210.

\title{
OPHTHALMIC HERPES ZOSTER WITH CONTRALATERAL HEMIPLEGIA
}

\author{
BY \\ G. ANASTASOPOULOS, K. ROUTSONIS, and C. S. IERODIAKONOU \\ From the Neuropsychiatric Clinic, University of Salonica, Greece
}

Cases of herpes zoster are not rare in everyday medical practice and the various neurological complications, such as post-herpetic neuralgias, are well known. Myelitis or encephalitis, on the other hand, are much rarer complications.

The following case admitted to the Neuropsychiatric Clinic of the University of Salonica is of special interest because of the focal cerebral lesions, which are very rare sequelae of herpes zoster.

A single man, aged 29, a farm worker from Konitsa in northern Greece, was admitted on April 29, 1957. There was nothing significant in his family or previous personal history. He consumed moderate quantities of tobacco and alcohol. He was right-handed.

On March 23, 1957, the patient developed a typical left ophthalmic herpes zoster, with slight ptosis of the left eyelid and diplopia on looking upwards. He recovered from his illness in a few days, and was well, except for slight pain in the left frontal region.

On April 26, while lying in bed, but before falling asleep, all of a sudden he discovered that he could not speak and at the same time that his right arm and leg were weak.

On examination, the skull was normal on palpation, without any bruit. The visual fields were normal. The left pupil was definitely larger than the right and reacted sluggishly to light and on accommodation. There was no nystagmus but slight ptosis of the left upper lid. The lower part of the right face was paralysed and the upper part was slightly affected. The pharyngeal reflex was sluggish and the tongue deviated to the right when protruded.

Voluntary movement in the upper limb was abolished on the right side. There was slight hypotonia on the right. The tendon reflexes were less marked on the right. Meyer's sign was absent on the right. There were no trophic disturbances. The abdominal and cremasteric reflexes were less brisk on the right side. Movements of the lower limbs were not fully performed and power was reduced on the right. The tendon reflexes were brisker on the right. Both plantar reflexes were extensor, more so on the right. Oppenheim's and Rossolimo's signs were present on the right. His gait was hemiplegic. All forms of sensation, including the discriminative, appeared to be normal, as far as could be judged in the presence of aphasia.
The patient did not speak spontaneously and on questioning he could hardly pronounce simple words and then only hesitantly. He could point to various named objects, but could not himself name them. He obeyed simple commands, though sometimes with a degree of perseveration, and understood written phrases, even complicated ones, but could not write even with the left hand.

No apraxia or agnosia was found.

Nothing abnormal was demonstrated in the cardio- is

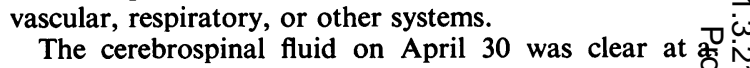
normal pressure (protein $44 \mathrm{mg}$. and sugar $60 \mathrm{mg}$. pe유 $\vec{\circ}$ $100 \mathrm{ml} ., 4$ lymphocytes, Pandy negative). The bloo 1 urea level was $40 \mathrm{mg}$., and blood sugar $70 \mathrm{mg}$. peß $100 \mathrm{ml}$. The E.S.R. (Westergren) was $5 \mathrm{~mm}$. in the first hour, $10 \mathrm{~mm}$. in the second hour. The Wassermann and Kahn reactions of blood and C.S.F. were negative

There were slight traces of protein in the urine. blood count gave $3,700,000$ red cells and 5,400 white. $\overrightarrow{0}$ cells per c.mm.; $\mathrm{Hb} 75 \%$. Radiographs of the skult were normal.

The patient's condition gradually but definitely improved, so that a month after the onset of the paralysis power was almost fully restored in the right leg, and less so in the right arm and face. The aphasic disturbances subsided to a great degree, but a slight difficulty in pronouncing unfamiliar words was left. There was slight sensory loss in the left frontal region. The tendon reflexes were brisker on the right and the plantar reflexes still extensor.

\section{The Literature}

The case is described above of a patient who, four $\frac{7}{0}$ weeks after the onset of left ophthalmic herpes zoster, presented with a right hemiplegia and expressive 3 . aphasia and agraphia. This case is of special interest $\stackrel{\rho}{\rho}$ because of the very great rarity of purely focal 3 lesions in the brain after herpes zoster, in contrast 음 to the generalized involvement of the brain (meningoencephalitis) which is not a very rare complication (Schiff and Brain, 1930; Biggart and Fisher, 1938; Krumholz and Luhan, 1945). Myelitides of various o kinds were also described, e.g., the Landry type 0 (Wohlwill, 1924; Schuback, 1930), the Brown- N Sequard type (Wilson, 1954), transverse myelitis 
(Bruce, 1907), and of course, the post-herpetic lesions of the lower motor neurone and the peripheral sensory pathways are well known (Taylor, 1895; Cornil, 1930; Carter and Dunlop, 1941; Taterka and O'Sullivan, 1943; de Gispert Cruz, 1955; Schwetz, 1955).

Brissaud, for the first time, in 1896, described two cases of hemiplegia following herpes zoster, but in neither was the cause certain. In the one the symptomatology was suggestive of subarachnoid haemorrhage, and in the other the hemiplegia was developed gradually, and the possibility of a cerebral tumour was not excluded.

In 1929 Faure-Beaulieu and Lhermitte described a case of herpes of the eleventh and twelfth dorsal segments with right hemiplegia. This case seems, however, to be rather, as other authors also accept, a case of cerebral thrombosis. A similar case was described by Lhermitte and Vermès (1930): a man of 75, who, three days after the onset of herpes zoster of the second cervical dermatome presented with a right hemiplegia. But this case was complicated by a positive Wassermann reaction and is not considered with certainty as due to the herpes zoster.

We consider the following cases of hemiplegia to be due definitely to herpes zoster.

(1) The case of Dumary in 1896 described by Baudouin and Lantuéjoul in 1919 in which, four weeks after a right ophthalmic zoster a left-sided hemiplegia occurred, without any signs of generalized encephalitis, or other general symptoms.

(2) The case described by Hughes (1951) in which, in a woman of 70 , with a right ophthalmic zoster, a left-sided hemiplegia occurred four weeks later.

(3) The case of Cope and Jones (1954) in which, in a woman of 54 and a month after the onset of a right ophthalmic zoster, a left hemiplegia was established in one day.

(4) The case of Gordon and Tucker (1945), in which a man of 26 , three weeks after the onset of a left ophthalmic zoster, presented with a paralysis of the right upper limb and face, and on the fourth week with paralysis of the right lower limb in addition. There was also a gross expressive aphasia. This case is the only one we could find in the literature in which aphasia accompanied hemiplegia after herpes zoster.

\section{Discussion}

The aphasic disturbances suggest a cortical or subcortical localization of the lesion, and the absence of such aphasic disturbances in three of the cases was evidently due to the right-sided localization of the lesion.

In all five cases of focal lesion of the brain, the herpes involved the ophthalmic branch of the 5 trigeminal nerve and the focal lesion was always in the ipsilateral hemisphere. There can be two possible explanations, either local meningo-encephalitis or arteritis leading to thrombosis.

Though no pathological study was possible in any of the cases, in view of their rapid recovery, the sudden onset without any prodromal symptoms and the rapid recovery in itself are in favour of a vascular lesion. Gordon and Tucker also consider that their case of hemiplegia and aphasia was due to a local haemorrhage or thrombosis; they exclude embolism because in their case, as in ours, no source of an embolus was evident.

Feyrter (1954) described a case of a woman with hypertension and a fatal apoplectic incident, in which histologically a necrotic arteritis of the type of periarteritis nodosa was found in the medulla, cerebellum, cerebrum, and meninges, mainly on the right side. Three months before her death the patient suffered from right-sided ophthalmic zoster with keratitis and iritis. After a thorough postmortem examination of other parts of the body, mainly the viscera, no signs of arteritis were found and for this reason Feyrter considers the arteritis of the brain to be due to the zoster. Many descriptions of necrotic arteritis in herpes zoster can be found in the literature, but it was not always considered to be due to the herpes zoster. Maybaum and Druss (1934) reported a case of periarteritis nodosa with pain and blebs on the pinna, auricle, and tympanic membrane six weeks before death.

It would be interesting if focal lesions of the brain due to herpes zoster without skin manifestations could be demonstrated. Aitken and Brain (1933) describe several cases of facial palsy without skin eruption, in which the diagnosis of herpes zoster was verified by complement-fixation tests. Feyrter (1954) and Denny-Brown, Adams, and Fitzgerald (1944), on the other hand, say that the sensory ganglia are not always involved in herpes zoster.

Denny-Brown et al. found necrotic lesions in the spinal ganglia in cases of spinal herpes zoster. Similar lesions with haemorrhages were described by von Bärensprung as early as 1862 and by Head and Campbell in 1900. Bruce (1907) thought that the spinal lesions in herpes zoster could be accounted for by an inflammatory thrombosis of the posterolateral or posterior cornual arteries. Denny-Brown's pathological findings were necrotic areas of remnants of cell bodies with zones of inflammation (lymphocytes and plasma cells), and they resembled infarct necrosis suggesting vascular occlusion. Strong evidence in favour of the latter was the finding of an artery of a ganglion actually thrombosed. Cuffing of the vessels and endothelial proliferation was a common finding. 
The thrombosis of vessels in herpes zoster, on the other hand, cannot be considered as a sequel of a generalized invasion of the central nervous system by the virus, because in that case the focal lesions would be expected in other parts of the central nervous system as well and not only ipsilaterally. It seems therefore that only a certain region of the brain around the Gasserian ganglion is involved, and that can even be shown in the case of Feyrter where, despite the rather generalized arteritis in the brain, lesions were more marked ipsilaterally to the invaded dermatome.

In contrast to the views of Gordon and Tucker, Cope and Jones accept for these cases of hemiplegia a direct spread of inflammation from the Gasserian ganglion to the corticospinal tract, and they thus try to explain the steady onset of hemiplegia three to four weeks after the onset of the skin eruption.

It may be significant that, in contrast to the usual finding of an increased number of cells in the cerebrospinal fluid, in our case the sample of fluid taken a few days after the onset of the paralysis contained only four cells (confirmed later by another lumbar puncture showing seven cells), and in Gordon and Tucker's case three cells and normal protein were found. This points to the fact that the meninges are not necessarily involved, as should be the case in a direct spread.

We think that there is a ganglionitis with secondary involvement of nearby vessels in the form of an arteritis, needing a certain period of time to lead to thrombosis, and thus the difference in the time of onset of the herpes and the focal symptoms can be explained. If, on the other hand, one accepts that there is simultaneous inflammatory involvement of the vessels, then the formation of a clot in a large cerebral vessel, later driven away and occluding smaller vessels, may be a plausible explanation.

It is noteworthy that focal lesions of the brain are always associated with herpes zoster of the ophthalmic branch of the trigeminal nerve, which is in close relationship to the middle cerebral artery, especially in its first part where the lenticulo-striate arteries arise to enter the anterior perforated substance and supply the internal capsule.

\section{Summary}

A case of right-sided hemiplegia with expressive aphasia following left ophthalmic zoster is described. On attempting to review the literature of focal cerebral lesions following herpes zoster, only four such cases could be traced. These all caused hemiplegia (one with aphasia), and all followed herpes zoster of the ophthalmic branch of the trigeminal nerve. Their common findings are discussed and the possible pathogenesis. The view is put forward that the vessels in the neighbourhood of the Gasserian ganglion may be involved in the form of an arteritis, leading to a vascular incident in the ipsilateral hemisphere.

\section{REFERENCES}

Aitken, R. S., and Brain, R. T. (1933). Lancet, 1, 19. Bärensprung, F. G. F. von (1862). Ann. d. Char.-Krankenh. zu Berl., W

Baudouin, E., and Lantuéjoul, P. (1919). Gaz. Hôp. (Paris), 92, 1293

Biggart, J. H., and Fisher, J. A. (1938). Lancet, 2, 944.

Brissaud (1896). J. Méd. Chir. prat., 67, 209.

Bruce, A. (1907). Rev. Neurol. Psychiat., 5, 885.

Carter, A. B., and Dunlop, J. B. W. (1941). Brit. med. J., 1, 234

Cope, S., and Jones, A. T. (1954). Lancet, $2,898$.

Cornil, L. (1930). Rev. neurol. (Paris), 1, 280.

Denny-Brown, D., Adams, R. D., and Fitzgerald, P. J. (1944). Arch Neurol. Psychiat. (Chicago), 51, 216.

Faure-Beaulieu, M., and Lhermitte, J. (1929). Rev. neurol. (Paris) 1, 1250 .

Feyrter, F. (1954). Zbl. ges. Neurol. Psychiat., 130, 188

Gispert Cruz, I. de (1955). Med. clin. (Barcelona), 24, 414. Gordon, I. R. S., and Tucker, J. F. (1945). J. Neurol. Psychiat.;

Head, H., and Campbell, A. W. (1900), Brain, 23, 353.

Hughes, W. N. (1951). Neurology, 1, 167.

Krumholz, S., and Luhan, J. A. (1945). Arch. Neurol. Psychiat. (Chicago), 53, 59.

Lhermitte, J., and Vermès, Y. (1930). Rev. neurol. (Paris), 1, 1231 Maybaum, J. L., and Druss, J. G. (1934). Arch. Otolaryng. (Chicago) 19, 574.

Schiff, C. I., and Brain, W. R. (1930). Lancet, 2, 70.

Schuback, A. (1930). Z. ges. Neurol. Psychiat., 123, 424.

Schwetz, F. (1955). Mschr. Ohrenheilk., 89, 88.

Taterka, J. H., and O'Sullivan, M. E. (1943). J. Amer. med. Ass. 122, 737 .

Taylor, F. (1895). Guy's Hosp. Rep., 52, 37.

Wilson, S. A. K. (1954). Neurology, Vol. 2, p. 778. Butterworth, London.

Wohlwill, F. (1924). Z. ges. Neurol. Psychiat., 89, 171. 